\title{
Overview of the Electricity Market for Household Customers in Bulgaria in the Period 2004 - 2017
}

\author{
$\mathrm{PhD}$ candidate Nevena Petrova \\ University of Economics - Varna \\ nevadp@abv.bg
}

\begin{abstract}
The purpose of this study is to discuss the electricity market in Bulgaria in the context of research and analysis of the electricity market for household customers and to outline the main trends in its development. In the course of the research the main priorities of Bulgaria in the field of energy have been outlined, which must be related to the development and modernization of the energy infrastructure, maintenance and renewal of the existing production capacities, which will lead to the creation of a competitive national energy market, integration in the regional energy market, and last but not least, to integration into the European Union's common energy market.
\end{abstract}

Keywords: electricity, electricity market, Energy and water regulatory commission.

JEL Code: L6; doi:10.36997/IJUSV-ESS/2019.8.2.189

\section{Въведение}

Съвременният начин на живот е немислим без производството и потреблението на енергия. От съществено значение за повишаване на жизнения стандарт на населението и икономическото развитие на всяка страна е наличието на източници на енергия и сигурен достъп до тях. Важен фактор за подобряването на сигурността на енергийните доставки, за преодоляването промените в климата, зависимостта от изкопаемите горива, от вноса на енергия от трети страни извън Европейския съюз са възобновяемите източници, заради своята устойчивост и приноса им за намаляване на емисиите на парникови газове. Обединена Европа е изправена пред редица проблеми в областта на енергетиката, които включват: растящата зависимост от вноса, недостатъчната диверсификация, високите и нестабилни цени на енергията, нарастващото търсене на енергия в глобален мащаб, рисковете за националната и европейската сигурност, засягащи държавите производителки и транзитните страни, нарастващите заплахи, свързани с изменението на климата, бавния напредък в областта на енергийната ефективност и пр. (European Parliament, 2019).

Целта на настоящата разработка е да се изследва пазара на електрическа енергия за битови клиенти в България и на тази основа да се очертаят основните тенденции в неговото развитие.

\section{1. Изследване на пазара на електрическа енергия за битови клиенти в България}

Основни приоритети на България на енергийния пазар са свързани с развитие и модернизиране на енергийната инфраструктура, при необходимост изграждане на нови производствени мощности, поддръжка и обновяване на съществуващите, което да доведе до създаване на конкурентен национален енергиен пазар, интегриране в регионалния енергиен пазар и не на последно място, до обединяване с общия енергиен пазар на ЕС. Търсенето и предлагането са двете основни променливи на пазара, чиито изменения са определящи за неговото равновесие. В таблица 1 са приведени данни за динамиката в изменението на структурата на основни показатели за потребена енергия в България за периода 2004 - 2017 г., измерени в процент.

Данните сочат, че средно за периода на стопанския сектор се падат 76,24\%, а на битовия сектор средно около $23,76 \%$ от крайното потребление на енергия. Посоченото съотношение определя стопанския приоритет на енергийното потребление, според което три от всеки четири единици се употребяват в основните стопански дейности на националната 
икономика и само една от четири е използвана за задоволяване на енергийните нуждите на домакинствата. Най-голям е делът на индустриалния сектор със средногодишен показател за периода 2004 - 2017 г. от 32,12\%, следван от транспортния сектор с много близки стойности от почти $31 \%$ и всички останали сектори около $13 \%$. При домакинствата през целия период се наблюдават леки колебания в относителния дял, който те имат в общото потребление на енергия от най-ниското значение 20,98\% през 2007 г. до най-високото 26\% през 2011 г., като през последните три години тенденцията е относителният им дял да се увеличава, макар и с бавни темпове. На фиг. 1 е видно, че през 2004 г. процентното съотношение между отделните групи потребители запазва своето статукво, докато през 2017 г. (вж. фиг. 2) транспортният сектор бележи ръст в енергийното потребление спрямо 2004 г. от почти 8\% за сметка на потребителите от индустриалния сектор.

Таблица 1. Динамика в изменението на структурата на основни показатели за потребена енергия в България за периода 2004 - 2017 г. (\%)

\begin{tabular}{|c|c|c|c|c|}
\hline \multirow{2}{*}{ Години } & \multicolumn{3}{|c|}{ Крайно енергийно потребление за страната } \\
\cline { 2 - 5 } & $\begin{array}{c}\text { Енергийно } \\
\text { потребление на } \\
\text { домакинствата }\end{array}$ & $\begin{array}{c}\text { Индустриален } \\
\text { сектор }\end{array}$ & $\begin{array}{c}\text { Транспортен } \\
\text { сектор }\end{array}$ & Други сектори \\
\hline 2004 & 22,769 & 39,944 & 26,455 & 10,831 \\
\hline 2005 & 21,763 & 38,012 & 28,299 & 11,926 \\
\hline 2006 & 21,684 & 36,983 & 28,692 & 12,640 \\
\hline 2007 & 20,984 & 38,789 & 28,163 & 12,064 \\
\hline 2008 & 21,958 & 35,924 & 29,966 & 12,152 \\
\hline 2009 & 24,942 & 28,862 & 32,581 & 13,616 \\
\hline 2010 & 25,755 & 29,401 & 30,938 & 13,906 \\
\hline 2011 & 26,005 & 29,590 & 30,229 & 14,177 \\
\hline 2012 & 25,800 & 28,314 & 31,962 & 13,924 \\
\hline 2013 & 25,845 & 29,823 & 30,220 & 14,112 \\
\hline 2014 & 24,369 & 29,494 & 32,828 & 13,309 \\
\hline 2015 & 23,355 & 28,897 & 34,204 & 13,544 \\
\hline 2016 & 23,663 & 27,754 & 34,326 & 14,257 \\
\hline 2017 & 23,810 & 27,944 & 34,146 & 14,100 \\
\hline
\end{tabular}

Източник: Евростат.

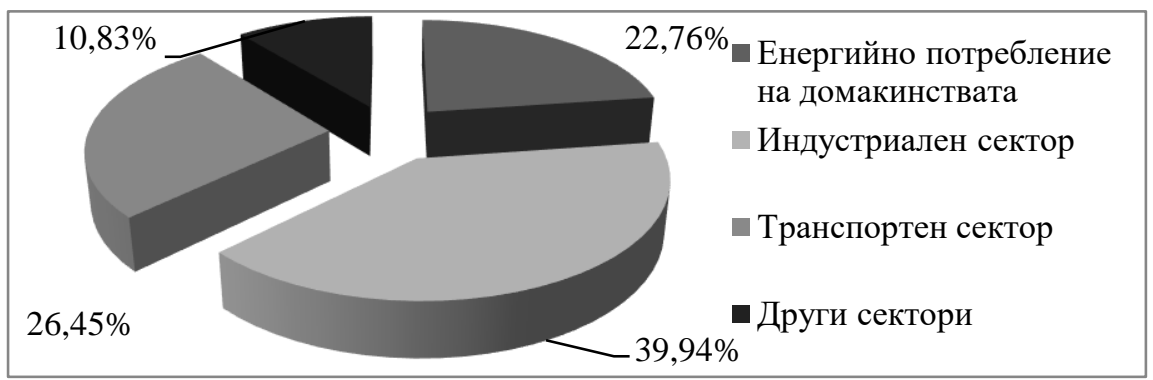

Фигура 1. Структурата на основни показатели за потребена енергия в България през 2004 г.

През 2017 г. потреблението на домакинствата е нараснало с 11,23\% в сравнение с 2004 г., а в сравнение с 2016 г. с 2,96\%. Аналогична ситуация наблюдаваме и в индустрията, транспорта и другите сектори, където в сравнение с 2004 г. през 2017 г. е регистриран ръст от 4,94\%, а в сравнение с 2016 г. , когато относителното тегло е било 2,12\%. 


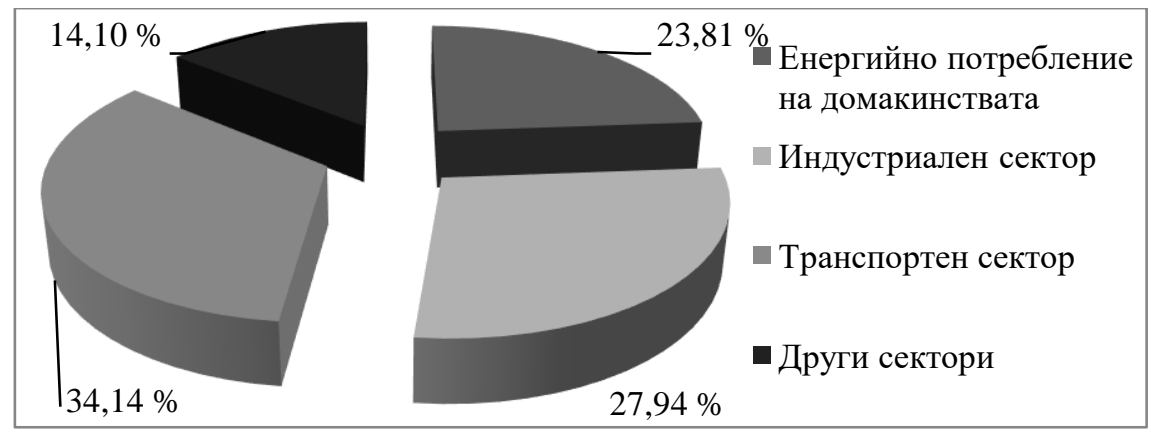

Фигура 2. Структурата на основни показатели за потребена енергия в България през 2017 г.

От гледна точка на търсенето, пазарът на дребно се състои от два сегмента - битови клиенти и небитови клиенти. Общият брой небитови клиенти през 2017 г. е 606055 броя. Общото потребление на пазара на небитови клиенти е $13050 \mathrm{GWh}$ годишно. $9931 \mathrm{GWh}$ е доставена на свободния пазар. Доставките на 469645 броя небитови клиенти се осъществяват по регулирани цени. Делът на небитови клиенти, излезли на свободния пазар до 2017 г. е 23 \%. Общият брой битови клиенти през 2017 г. е 4476040 броя. Общото потребление на електрическа енергия на пазара на дребно е $11068 \mathrm{GWh}$ годишно. Обемът доставена енергия по свободни цени на пазара на битови клиенти е 13 GWh през 2018 г., което представлява 0,12 \% от доставките на електрическа енергия на пазара на дребно (KEVR, 2018).

Несъмнено е, че промените в търсенето на стопанските субекти предопределят във висока степен колебанията в общото крайно потребление на страната, тъй като те имат найголемия енергиен разход. Структурните промени в енергийното потребление са израз на трансформационните процеси и растящата значимост на определени икономически дейности на националното стопанство, което е предизвикано от тяхното разширяване за сметка на свиването на други, но може да бъде и ефект от подобрената енергийна ефективност в традиционните сектори на националната икономика.

Поради спецификата на енергийния пазар при настъпили промени в търсенето, трябва да последва незабавна промяна в предлагането, тоест производствените мощности трябва да са достатъчни, за да посрещнат евентуален ръст в търсенето на енергия. Разбира се търсенето може да бъде задоволявано освен от националното производство и чрез внос от регионален и дори от европейския енергиен пазар. Тенденцията, която се наблюдава е, че в България брутната налична енергия през последните шест години намалява с от 0,56\% през 2017 г. до 10,29\% през 2013 г., изчислено на база 2004 г., като през 2017 г. намалението е минимално, което води до възможности за прогнозиране на евентуално увеличение в следващи периоди (вж. табл. 2). Съпоставена с предходната 2016 г. резултатите през 2017 г. са обнадеждаващи от гледна точка на процентното изменение на брутна налична енергия, а именно видно е увеличение с 3,49 \%. Тази промяна е индикация за възстановяването и новосъздаването на енергийни мощности в страната и основно в областта на ВЕИ. На фона на тези положителни тенденции логично е да има ръст и на потреблението.

Въз основа на проведения анализ можем да обобщим, че към момента наличните производствени мощности имат потенциала да задоволяват нарасналото потребление на енергия и не съществува необходимост на този етап да бъдат изграждани нови такива със съществен капацитет. Следователно, тук трябва да се реализира стратегията за устойчиво възпроизводство и приоритет върху търсенето на зелени енергийни решения и такива с понисък въглероден отпечатьк. 
Според икономическата теория върху търсенето на дадена стока влияние могат да оказват редица макро- и микроикономически фактори. Когато се говори за съвкупното търсене на определена стока, логично е на първо място нейното търсене да се свърже с основните макроикономически фактори като например брутния вътрешен продукт (БВП). Растежът на БВП е пряко свързан с развитието на икономиката, а функционирането на икономиката е свързано с консумирането на електроенергия, тоест налице е връзка между растежа или обратно - спада в БВП и потреблението на електроенергия ( Gushterov, N., 2016).

Таблица 2. Динамика в развитието на брутната налична енергия в България за периода $2004-2017$ г.

\begin{tabular}{|c|c|c|c|c|c|c|c|}
\hline \multirow[t]{3}{*}{ Години } & \multirow{2}{*}{$\begin{array}{c}\text { Брутна } \\
\text { налична } \\
\text { енергия }\end{array}$} & \multicolumn{2}{|c|}{$\begin{array}{c}\text { Абс. прираст на } \\
\text { брутната налична } \\
\text { енергия в хил. т н. е. }\end{array}$} & \multicolumn{2}{|c|}{$\begin{array}{c}\text { Темп на } \\
\text { снижение/увеличение на } \\
\text { брутната налична } \\
\text { енергия в \% }\end{array}$} & \multicolumn{2}{|c|}{ Индекси в \% } \\
\hline & & 2 & 3 & 4 & 5 & 6 & 7 \\
\hline & хил. т н.е. & баз. = 2004 & вер. & баз. = 2004 & вер. & баз. = 2004 & вер. \\
\hline 2004 & 19085,229 & 0,0 & - & 0,000 & - & 100,000 & - \\
\hline 2005 & 20197,252 & 1112,0 & 1112,0 & 5,827 & 5,827 & 105,827 & 105,827 \\
\hline 2006 & 20798,926 & 1713,7 & 601,7 & 8,979 & 2,979 & 108,979 & 102,979 \\
\hline 2007 & 20406,916 & 1321,7 & $-392,0$ & 6,925 & $-1,885$ & 106,925 & 98,115 \\
\hline 2008 & 20164,839 & 1079,6 & $-242,1$ & 5,657 & $-1,186$ & 105,657 & 98,814 \\
\hline 2009 & 17740,769 & $-1344,5$ & $-2,424,1$ & $-7,045$ & $-12,021$ & 92,955 & 87,979 \\
\hline 2010 & 17969,125 & $-1116,1$ & 228,4 & $-5,848$ & 1,287 & 94,152 & 101,287 \\
\hline 2011 & 19209,803 & 4,6 & $1,240,7$ & 0,653 & 6,904 & 100,653 & 106,904 \\
\hline 2012 & 18431,218 & $-654,0$ & $-778,6$ & $-3,427$ & $-4,053$ & 96,573 & 95,947 \\
\hline 2013 & 17122,176 & $-1963,1$ & $-1309,0$ & $-10,286$ & $-7,102$ & 89,714 & 92,898 \\
\hline 2014 & 17925,481 & $-1159,7$ & 803,3 & $-6,077$ & 4,692 & 93,923 & 104,692 \\
\hline 2015 & 18731,649 & $-353,6$ & 806,2 & $-1,853$ & 4,497 & 98,147 & 104,497 \\
\hline 2016 & 18338,406 & $-746,8$ & $-393,2$ & $-3,913$ & $-2,099$ & 96,087 & 97,901 \\
\hline 2017 & 18978,417 & $-106,8$ & 640,0 & $-0,560$ & 3,490 & 99,440 & 103,490 \\
\hline
\end{tabular}

Повишаването на енергийната ефективност е сред ключовите цели, които си поставят повечето държави от развития свят и България не е изключение от тези тенденции. Необходимостта от подобряване на енергийната ефективност в страната е основен приоритет на национално равнище, който се реализира чрез създаване на институционални, нормативни и финансови условия за осъществяване на националната политика, която е формализирана в приетия Закон за енергийната ефективност, което е предпоставка за успешното интегриране на националния енергиен сектор в европейския енергиен пазар.

Показателят, който се използва за оценка на енергийната ефективност, е енергийна интензивност и се изчислява като съотношение между брутното вътрешно потребление на енергия (в тонове нефтен еквивалент) и БВП (по постоянни цени на 2010 г. в евро).

На фиг. 3 са показани индексите на изменението на БВП, брутното вътрешно потребление и енергийната интензивност в периода $2004-2017$ г., като индексът за 2004 г. е приет за 100\%. Тенденцията, която се наблюдава в дългосрочен план, е на нарастване на БВП с над $43 \%$ и намаление на брутното вътрешно потребление с по-малко от $1 \%$. Енергийната интензивност през 2017 г. намалява до 33\% спрямо нейното равнище през 2004 г. През 2017 г. БВП нараства с 3,7\% в сравнение с предходната 2016 г., крайното вътрешно потребление на енергия се увеличава с по-малко от $1 \%$, а енергийната интензивност гравитира около стойностите от 2016 г. 


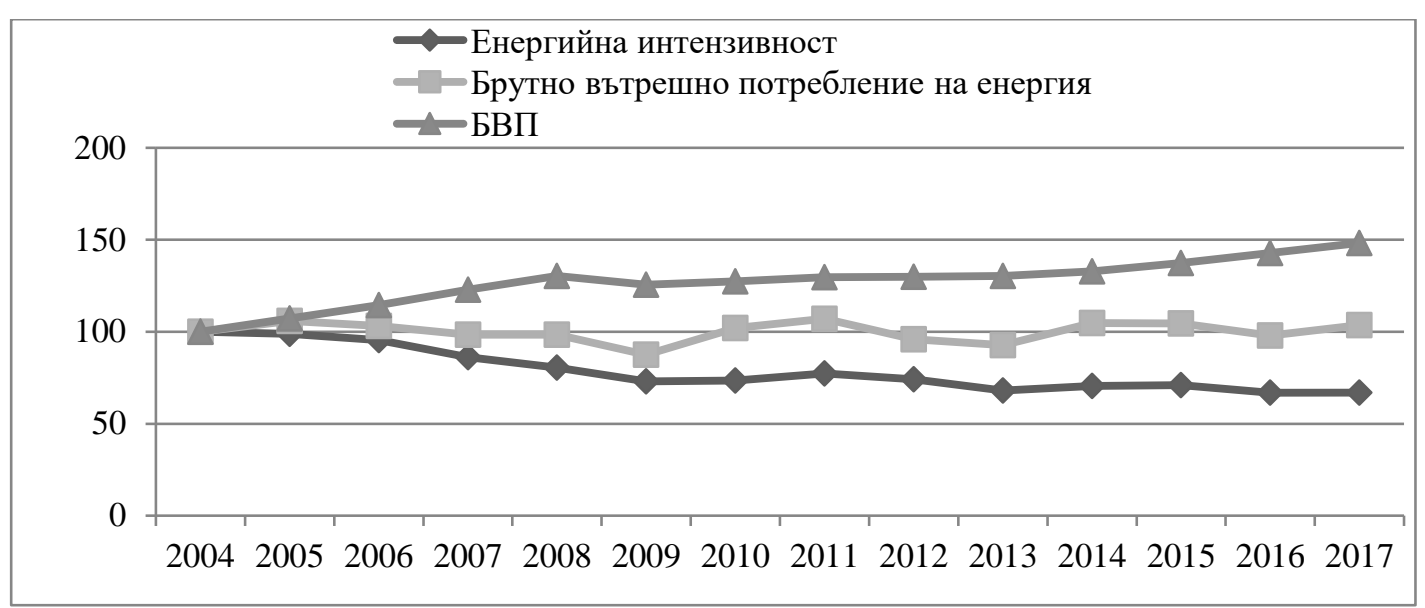

Източник: НСИ и Евростат

Фигура 3. БВП, брутно вътрешно потребление на енергия и енергийна интензивност в периода $2004-2017$ г., индекси $2004=100$.

Запазват се резултатите от 2016 г., когато е прекъсната тенденцията на нарастване на енергийната интензивност от предходните 2014 и 2015 г., а снижаването на енергийната интензивност на БВП е една от главните енергийни цели за устойчиво развитие на икономиката, която е постижима чрез спестяване на енергията при крайното потребление, както и в процеса на преобразуване на енергията, в това число намаляване загубите при преноса и разпределението на енергия, увеличаване ефективността на работа на термичните централи, повишаване дела на енергията, произведена по високоефективен комбиниран начин и други.

Следователно формирането на благоприятната картина може да бъде резултат от протичането на два паралелни процеса, където от една страна се подобрява енергийната ефективност на националното стопанство и неговите сектори, а от друга успешно се развиват икономически дейности, който са ниско зависими от енергийни ресурс, но въпреки това допринасят за създаването на БВП.

За да достигне до пазара електрическата енергия трябва да бъде произведена от конвенционални (въглища, нефт, природен газ, атомна енергия, горливи шисти и др. източници) и възобновяеми енергийни източници. От стратегическо значение в макроикономическата рамка на страната е нейната енергийна независимост, която се свързва c диверсификацията на източници на енергия, измерена с показателя енергийната зависимост, който показва степента, до която икономиката разчита на вноса, за да посрещне енергийните си нужди. Според данни на Евростат по показателя енергийна зависимост България отчита през последните осем години значително по-ниски стойности от средните за страните-членки на ЕС-28 (вж. фиг. 4).

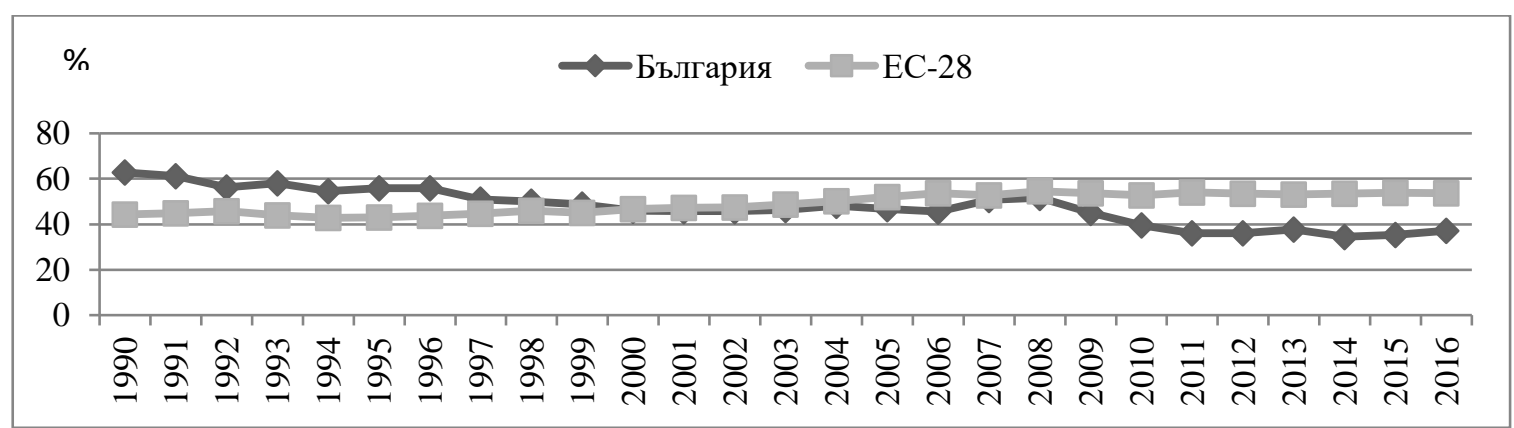

Източник: Eurostat, Energy dependence. Достьпен на: <https://ec.europa.eu/eurostat/ tgm/table.do?tab=table \&init $=1 \&$ language $=e n \& p c o d e=t 2020 \_r d 320 \&$ plugin $=1>(11.09 .2019)$. Фигура 4. Динамика в развитието на енергийната зависимост на ЕС-28 и България за периода 1990 - 2016 г. 
Показателят е изчислен като нетен внос, разделен на сумата на брутното вътрешно потребление на енергия плюс морската бункеровка (NSI, 2019).

Основен местен ресурс за производство на електроенергия на България са лигнитните въглища. Ядрената енергия се отчита за местен източник и в значителна степен допринася за подобряване на енергийната независимост (Ministerstvo na energetikata, 2017), тоест нейната по-ниска зависимост от външни енергийни източници.

В страната производителите на електрическа енергия са „Националната електрическа компания“ ЕАД („НЕК“ ЕАД), Възобновяеми енергийни източници (ВЕИ), Високоефективно комбинирано производство (ВЕКП), Топлоелектрически централи (ТЕЦ), Атомна електроцентрала (АЕЦ), Водноелектрически централи (ВЕЦ).

Важен участник на електроенергийния пазар e „Националната електрическа компания“ ЕАД („НЕК“ ЕАД), която е еднолично акционерно дружество със седалище в гр. София. Собственик на капитала на „НЕК“ ЕАД е „Български енергиен холдинг“ ЕАД („БЕХ“ ЕАД), създаден на 18.09.2008 г. с решение на Министъра на икономиката и енергетиката, чрез преименуване на „Булгаргаз холдинг“ ЕАД. „БЕХ“ ЕАД е акционерно дружество със 100 \% държавно участие. В него се включват мини „Марица-изток“ ЕАД, ТЕЦ „Марицаизток 2“ ЕАД, АЕЦ „Козлодуй“ ЕАД, „НЕК“ ЕАД, „ЕСО“ ЕАД, „Булгаргаз“ ЕАД, „Булгартрансгаз“ ЕАД и „Булгартел“ ЕАД. Групата притежава основните предприятия за производство на електроенергия в страната, както и мрежата за пренос на електроенергия и мрежите за пренос и транзит на природен газ. Важно е да се подчертае и ролята на „БЕХ“ ЕАД на обществен доставчик на регулиран пазар, която я преврьща в стратегически значимо държавно дружество (Bulgarian Energy Holding EAD).

На регулирания пазар крайният снабдител осигурява снабдяването с електрическа енергия на обекти на битови и небитови крайни клиенти (мальк бизнес), присъединени към електроразпределителната мрежа на ниво ниско напрежение, когато не се снабдяват от друг доставчик. Разпределението на електрическа енергия се осъществява от регионални компании, които притежават лицензия за дейността снабдяване с електрическа енергия от краен снабдител (вж. табл. 3).

Таблица 3. Основни характеристики на операторите на електроразпределителната мрежа в България към 01.06.2019 г.

\begin{tabular}{|c|c|c|c|}
\hline Характеристики & „Енерго-Про“6 & ,EBH“6 & „ЧЕЗ Груп“6 \\
\hline $\begin{array}{l}\text { 1. Страна на произход и } \\
\text { година, от която оперира на } \\
\text { българския енергиен пазар }\end{array}$ & Чехия (2012) & Австрия (2005) & Чехия (2004) \\
\hline 2. Мажоритарни акционери & „Енерго-Про“ а.с. Чехия & EVN AG Австрия & „ЧЕЗ““ а.с. Чехия \\
\hline 3. Обхват (DV, 2018) & $\begin{array}{c}\text { Северен централен и } \\
\text { Североизточен райони }\end{array}$ & $\begin{array}{l}\text { Южен Централен и } \\
\text { Югоизточен райони }\end{array}$ & $\begin{array}{c}\text { Северозападен и } \\
\text { Югозападен } \\
\text { райони } \\
\end{array}$ \\
\hline $\begin{array}{l}\text { 4. Оператори на } \\
\text { електроразпределителната } \\
\text { мрежа }\end{array}$ & $\begin{array}{c}\text { „Електроразпределение } \\
\text { Север” АД }\end{array}$ & $\begin{array}{c}\text { „Електроразпределение } \\
\text { Юг“ (ЕР ЮГ) }\end{array}$ & $\begin{array}{c}\text { „ЧЕЗ } \\
\text { Разпределение } \\
\text { България” АД } \\
\end{array}$ \\
\hline 5. Крайни снабдители & $\begin{array}{c}\text { „Енерго-Про Продажби” } \\
\text { АД }\end{array}$ & $\begin{array}{c}\text { „ЕВН България } \\
\text { Електроснабдяване” АД }\end{array}$ & $\begin{array}{l}\text { „ЧЕЗ Електро } \\
\text { България” АД }\end{array}$ \\
\hline $\begin{array}{l}\text { 6. Търговия с електрическа } \\
\text { енергия и координатор на } \\
\text { стандартна балансираща } \\
\text { група }\end{array}$ & $\begin{array}{c}\text { „Енерго-Про Енергийни } \\
\text { Услуги“ ЕООД }\end{array}$ & EVN Tрейдинг & $\begin{array}{c}\text { „ЧЕЗ Трейд } \\
\text { България““ЕАД }\end{array}$ \\
\hline
\end{tabular}

Следва да отбележим, че и трите електроразпределителни компании имат сравнително подобни структурни поделения, като единствено „ЧЕЗ Груп“ изгражда и 
дружества за услуги в областта на информационните и комуникационни технологии и за предоставяне на цялостни енергийни решения.

Освен регулиран сегмент на електроенергийния пазар в България, функционира и свободният, където оперират множество участници, чиято дейност е свързана с:

- Производство на електрическа енергия: АЕЦ, ТЕЦ МИ 2, НЕК ВЕЦ, ТЕЦ, ВЕИ $>4 \mathrm{MW}$, ВЕКП>4MW.

- Пренос на електрическа енергия: „Електроенергиен системен оператор“ ЕАД („ЕСО“ ЕАД).

- Борсови операции с електрическа енергия: „Българска независима енергийна борса“ ЕАД (БНЕБ).

- Търговия с електрическа енергия: тьрговци.

- Разпределение на електрическа енергия: Електроразпределителни предприятия (ЕРП).

- Закупуване на електрическа енергия: битови абонати, предприятия от малкия бизнес, индустриални клиенти и клиенти извън страната (износ).

Причините за нарастващия интерес бихме могли да свържем със старта през 2004 г. на либерализацията на енергийния пазар и с тенденцията за постепенното премахване на регулираните цени, каквито са насоките на Европейската комисия (European Commission, 2014), тъй като в много държави-членки цените на електроенергията не следват търсенето и предлагането и се регулират от публичните органи, което възпрепятства появата на нови участници на пазара, а основна характеристика на либерализирания пазар е наличието на конкуренция между пазарните участници. Това от своя страна ще доведе до повишаване на ефективността на производителите и търговците на електроенергия и намаляване на техните разходи, и съответно до намаляване на продажните цени. Подобна основна цел преследва, защита на най-уязвимия елемент на веригата - крайните битови потребители, които имат ограничени възможности за своето самостоятелно участие на енергийния пазар.

На практика на свободния електроенергиен пазар начините, по които се осъществява търговията, са два:

- чрез директни двустранни договори с производители;

- чрез покупки на електрическа енергия от борса (БНЕБ) - пазар „Ден-напред” и „В рамките на деня".

И при двата начина на търговия крайният потребител може да бъде пряк контрагент или сделките да са възложени на лицензиран търговец.

Интересът на потребителите към свободния пазар на електроенергия през периода 2004 - 2017 г. бележи своите пикове и спадове (вж. табл. 4). Докато през 2004 г. потребителите, включили се на свободния пазар на електроенергия, са 7 бр., то през 2017 г. техният брой вече е 136410 бр., тоест наблюдава се драстично увеличение, което се дължи на преимуществата на свободния пазар пред регулирания и повишената осведоменост на потребителите по отношение на либерализацията на пазара на електроенергия - нейните предимства и недостатъци. Големият скок в броя на потребителите на свободен пазар през 2013 г. се дължи на започналото активно преминаване на клиенти, присъединени към мрежа средно напрежение $(6-20 \mathrm{kV})$ от регулирания на свободния пазарен сегмент. От 2014 г. до 2017 г. се наблюдава трайна тенденция към увеличаване на потребителите на свободен пазар средногодишно с 2,88\%, като увеличението през 2017 г. в сравнение с 2016 г. е 3,78\%. Трябва да отбележим и факта, че същевременно има потребители, които се връщат на регулирания пазар, тоест съществува така нареченият обратен миграционен процес и той е свързан с динамиката на цените на свободния пазар и факта, че не винаги цените, които са предложени от търговците, са по-ниски от тези на регулирания пазар. Свободният пазар на 
електроенергия за разлика от регулирания е изключително динамичен. На него много фактори могат да оказват влияние върху цените на електроенергията, като някои от основните са: цени на горива, въглища, въглеродни емисии, метеорологични условия, политически фактори, международна стопанска конюнктура и други. Следователно, тук действат силите на систематичните и несистематични фактори на пазарната среда. Докато в действието на регулирания пазар има голям субективно-административен елемент, изразен в решенията на КЕВР и тяхната често пъти несъвместима политическа, икономическа и социална пристрастност.

Таблица 4. Динамика в развитието на потребителите на електроенергия на свободния пазар в Република България за периода 2004 - 2017 г.

\begin{tabular}{|c|c|c|c|c|c|c|c|}
\hline \multirow{3}{*}{ Години } & \multirow{2}{*}{$\begin{array}{c}\text { Потребители } \\
1 \\
\end{array}$} & \multicolumn{2}{|c|}{$\begin{array}{c}\text { Абс. прираст на броя на } \\
\text { потребителите }\end{array}$} & \multicolumn{2}{|c|}{$\begin{array}{c}\text { Темп на } \\
\text { снижение/увеличение на } \\
\text { броя на потребителите в \% }\end{array}$} & \multicolumn{2}{|c|}{ Индекси в \% } \\
\hline & & 2 & 3 & 4 & 5 & 6 & 7 \\
\hline & брой & баз. = 2004 & вер. & баз. $=2004$ & вер. & баз. $\mathrm{i}=2004$ & вер.і \\
\hline 2004 & 7 & 0 & - & 0 & - & 0,00 & - \\
\hline 2005 & 14 & 7 & 7 & 100,00 & 100,00 & 200,00 & 200,00 \\
\hline 2006 & 33 & 26 & 19 & 371,42 & 135,71 & 471,42 & 235,71 \\
\hline 2007 & 62 & 55 & 29 & 785,71 & 87,87 & 885,71 & 187,87 \\
\hline 2008 & 57 & 50 & -5 & 714,28 & $-8,06$ & 814,28 & 91,93 \\
\hline 2009 & 61 & 54 & 4 & 771,42 & 7,01 & 871,42 & 107,01 \\
\hline 2010 & 65 & 58 & 4 & 828,57 & 6,55 & 928,57 & 106,55 \\
\hline 2011 & 77 & 70 & 12 & 1000,00 & 18,46 & 1100,00 & 118,46 \\
\hline 2012 & 105 & 98 & 28 & 1400,00 & 36,36 & 1500,00 & 136,36 \\
\hline 2013 & 2096 & 2089 & 1991 & 29842,85 & 1896,19 & 29942,85 & 1996,19 \\
\hline 2014 & 4867 & 4860 & 2771 & 69428,57 & 132,20 & 69528,57 & 232,20 \\
\hline 2015 & 13105 & 13098 & 8238 & 187114,28 & 169,26 & 187214,28 & 269,26 \\
\hline 2016 & 36069 & 36062 & 22964 & 515171,42 & 175,23 & 515271,42 & 275,23 \\
\hline 2017 & 136410 & 136403 & 100341 & 1948614,28 & 278,19 & 1948714,28 & 378,19 \\
\hline
\end{tabular}

Източник: Асоциацията на търговците на електроенергия в България (АТЕБ). Достъпен на: $<$ http://ateb.bg/naзар/> (11.03.2019).

При средно развити икономики, каквато е тази на България, факторите за ускоряване на икономическия растеж включват преди всичко по-ефективно използване на наличните, традиционни ресурси на страната - земя, енергия, природни дадености, географско разположение, работна сила и др. За ограничен период от 5-7 години при този подход може да се очаква увеличение на годишните темпове на растеж на БВП (Dimitrov, M., 2007).

\section{Заключение}

Основните приоритети на България по отношение на енергетиката трябва да са свързани с развитие и модернизиране на енергийната инфраструктура, поддръжка и обновяване на съществуващите производствени мощности, което да доведе до създаване на конкурентен национален енергиен пазар, интегриране в регионалния енергиен пазар и не на последно място, до пълноценно включване в общия енергиен пазар на ЕС. Следователно, две са основните приоритетни оси на развитие:

- първата, възпроизвеждане и обновяване на съществуващите, тоест тяхното 
привеждане към новите изисквания на технологиите и изискванията на определени стандарти и регламенти, което да бъде гарант за предвидимостта на пазарното предлагане и неговия потенциал за развитие при увеличено търсене;

- втората, устойчиво развитие и приоритет на ВЕИ и производство с ниськ въглероден отпечатък и тяхното участие както в енергийния микс, така и по отношение на задоволяване на пиковото потребителско търсене.

\section{References}

1. European Parliament (2019) Energiina politika: obshti printsipi. Dostupen na: <http://www.europarl.europa.eu/factsheets/bg/sheet/68/енергиина-политика-общипринципи> (24.09.2019).

2. KEVR (2018) Godishen doklad za Evropeiskata komisiya, s. 31. Dostupen na: <http://www.dker.bg/uploads/2018/EWRC_Report_EC_18.pdf> (30.09.2019).

3. Gushterov, N. (2016 ) Prognozirane turseneto na elektroenergiya ot stopanskite subekti v Bulgariya do 2021. // Godishen almanakh nauchni izsledvaniya na doktoranti, Svishtov: SA „D. A. Tsenov“, s. 169. Dostupen na: <https://dlib.uni-svishtov.bg/bitstream/handle/10610/ 3301/f3b65958176258532c9409724d34b9e8e059414f9582e7a2ca49c8419ed4e4d5.pdf?sequenc $\mathrm{e}=1 \&$ is Allowed $=\mathrm{y}>(30.09 .2019)$.

4. NSI (2019) Metodologichni belezhki. Dostupen na: <http://www.nsi.bg/sites/ default/files/files/metadata/Energy-4.7.Methodology.pdf> (03.09.2019).

5. Ministerstvo na energetikata (2017) Byuletin za sustoyanieto i razvitieto na energetikata, s. 4. Dostupen na:

https://www.me.government.bg/files/useruploads/files/buletin_energy_2017.pdf> (08.09.2019)

6. Bulgarian Energy Holding EAD (2019). Dostupen na: <https://www.bgenh.com/ page/3/\%D0\%9F\%D0\%BE\%D1\%80\%D1\%82\%D1\%84\%D0\%BE\%D0\%BB\%D0\%B8\%D0\% BE.html> (03.09.2019).

7. DV (2018) Raionite sa obosobeni, suglasno chl. 4 ot Zakona za regionalno razvitie. // obn. DV. br.50 ot 30 Mă 2008., izm. i dop. DV. br. 28 ot 29 Mart 2018. Dostupen na: <https://lex.bg/bg/laws/ldoc/2135589285> (12.09.2019).

8. European Commission (2014) Tseni i razkhodi na energiyata v Evropa. Dostupen na: <https://eur-lex.europa.eu/legal-content/BG/TXT/?uri=celex:52014DC0021> (30.09.2019).

9. Dimitrov, M. (2007) Osnovni momenti na strategiyata za uskoreno razvitie na bulgarskata ikonomika. - V: Studii za uskoreno razvitie na bulgarskata ikonomika, Sofiya: Goreks Pres, s. 11-30. 